\title{
S-16: Biathlon ve Buz Hokeyi Sporcularının Diz Fleksiyon ve Ekstansiyon Kas Kuvvetlerinin Karşılaştırılması
}

\author{
Bihter Akınoğlu ${ }^{1}$, Tuğba Kocahan ${ }^{2}$, Çağlar Soylư ${ }^{1}$, Necmiye Ün Yıldırım $^{1}$, Adnan Hasanoğlu ${ }^{2}$ \\ ${ }^{1}$ Ankara Yıldırım Beyazıt Üniversitesi, Sağlık Bilimleri Fakültesi, Fizyoterapi ve Rehabilitasyon Bölümü, Etlik \\ Doğu Kampüsü, Ankara \\ ${ }^{2}$ Gençlik ve Spor Bakanlığı, Spor Genel Müdürlüğü, Sağlık Işsleri Dairesi Başkanlığı, Eryaman, Ankara
}

\section{öz}

GiRiş: Biathlon kayaklı koşu ve tüfekli atışın bir araya getirildiği bir sporudur. Buz hokeyi, paten kaymanın temel beceri olduğu bir spordur. Aralıklı ve yüksek şiddette kayma, ivmelenme, hız ve yön değişiklikleri ile çeşitli manevra becerileri her iki spor branşının karakteristik özelliklerindendir. Birçok laboratuvar ve saha testleri antrenman programlarının planlanmasında sporcuların fiziksel yeterliliklerinin ölçülmesinde ve değerlendirilmesinde belirleyici olmaktadır. Özellikle bu sporcularda buz dışı ölçümlerde belirlenen $\mathrm{H} / \mathrm{Q}$ oranı ve bacak kuvvetleri arasındaki farkın, sağa ve sola yön değişimi içeren kayma performansları ile ileri kayma performansları arasında farkı belirleyici olabilmektedir.

AMAÇ: Bu çalışmanın amacı biathlon ve buz hokeyi sporcularının izokinetik diz fleksiyon ve ekstansiyon kas kuvvet profillerini karşılaştırmaktır.

GEREÇ-YÖNTEM: Çalışma, ortalama yaşları $17.64 \pm 1.32$ olan 7 kadın biathlon sporcusu ile ortalama yaşları $17.57 \pm 0.78$ olan 7 kadın buz hokeyi sporcusu ile gerçekleştirildi. İzokinetik değerlendirme 90-10 - fleksiyon açılarında konsantrik-konsantrik olarak 5 tekrarlı 60\%/sn. hızla ve 15 tekrarlı $240 \%$ sn. hızla maksimal diz fleksiyon ve ekstansiyon hareketleri bilateral yaptırıldı.

BULGULAR: Gruplar arasında yaş, kilo, boy ve VKi bakımından fark bulunmadı ( $p>0,05)$ (Tablo.1). Diz fleksörleri ve ekstansörlerinin her iki hız ve tarafta izokinetik kas kuvvetleri Biathlon sporcularında daha yüksek bulundu $(p<0,05)$. Sporcuların $H / Q$ peak tork oranı her iki açısal hızda da gruplar benzerdi. Kas kuvvet dengesi açısından gruplar incelendiğinde; 240\%/sn. hızda bu oran her iki tarafta hamstringler aleyhinde bulundu (Tablo.2). Her iki spor branşında sağ-sol taraf arasında bir asimetri olmadığı ve bu durumun literatür ile uyumlu belirlendi (Tablo.3) SONUÇ: Çalışmamızda diz fleksiyon ve ekstansiyon peak tork değerleri her iki açısal hızda biathlon sporcularında daha yüksek bulundu. Bunun sebebinin biathlon sporunun aerobik özelliği fazla olan bir spor olduğu için diz fleksör ve ekstansör kaslarının buz hokeyi sporcularına göre daha fazla yavaş kasılan kırmızı kas liflerini içermesine bağlı olduğunu düşünmekteyiz. 
Tablo1. Sporcuların Demografik Özellikleri

$\pm$

\section{BIATHLON (N=7) BUZ HOKEYI (N=7) P $\mathrm{X} \pm \mathrm{SD} \quad \mathrm{X} \pm \mathrm{SD}$}

\begin{tabular}{llll}
\hline Yaş (yıl) & $17,64 \pm 1,32$ & $17,57 \pm 0,78$ & 0,351 \\
\hline Kilo $(\mathbf{k g})$ & $59,57 \pm 5.19$ & $56,71 \pm 5,70$ & 0,244 \\
\hline Boy $(\mathbf{m})$ & $1,65 \pm 0,044$ & $1,67 \pm 0,05$ & 0,276 \\
\hline VKi $\left(\mathbf{k g} / \mathbf{m}^{2}\right)$ & $21,09 \pm 2,11$ & $20,27 \pm 1,52$ & 0,141 \\
\hline
\end{tabular}

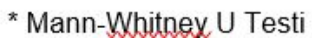

Tablo 2. Sporcularının Diz Hamstring/Quadriceps Peak Tork Oranı Yüzdesi (H/Q Oranı), Peak Tork Değerlerinin Karşılaştırılması

\begin{tabular}{|c|c|c|c|c|}
\hline & $\begin{array}{l}\text { BIATHLON } \\
(\mathrm{N}=7) \\
\mathrm{X} \pm \mathrm{SD}\end{array}$ & $\begin{array}{l}\text { BUZ HOKEYI } \\
(\mathrm{N}=7) \\
\mathrm{X} \pm \mathrm{SD}\end{array}$ & $\mathbf{P}^{*}$ & $Z$ \\
\hline $\begin{array}{l}\text { 60\% } / \text { Sn' De Dominant Taraf PT } \\
\text { Fleksiyon }\end{array}$ & $90,90 \pm 16,67$ & $68,50 \pm 9,72$ & $0,013^{\circ}$ & $-2,492$ \\
\hline $\begin{array}{l}\text { 60\%/Sn' De Dominant Taraf PT } \\
\text { Ekstansiyon }\end{array}$ & $184,77 \pm 36,13$ & $142,20 \pm 25,17$ & $0,025^{\circ}$ & $-2,236$ \\
\hline $\begin{array}{l}\text { 60\%/Sn' De Nap-dominant Taraf } \\
\text { PT Fleksiyon }\end{array}$ & $84,70 \pm 14,30$ & $73,21 \pm 12,28$ & 0,224 & $-1,215$ \\
\hline $\begin{array}{l}60^{\circ} / \mathrm{Sn}^{\prime} \text { ' De Non_dominant Taraf } \\
\text { PT Ekstansiyon }\end{array}$ & $181,35 \pm 41,54$ & $137,72 \pm 25,38$ & $0,048^{\circ}$ & $-1,981$ \\
\hline $\begin{array}{l}240 \% \text { Sn' De Dominant Taraf PT } \\
\text { Fleksiyon }\end{array}$ & $66,30 \pm 9,65$ & $51,58 \pm 11,21$ & $0,025^{\circ}$ & $-2,239$ \\
\hline $\begin{array}{l}\text { 240\% \$n' De Dominant Taraf PT } \\
\text { Ekstansiyon }\end{array}$ & $104,04 \pm 14,04$ & $85,05 \pm 12,90$ & $0,048^{\circ}$ & $-1,981$ \\
\hline $\begin{array}{l}240^{\circ} / \$ n^{\prime} \text { 'De Non_dominant } \\
\text { Taraf PT Fleksiyon }\end{array}$ & $68,47 \pm 9,95$ & $48,71 \pm 11,01$ & $0,011^{\circ}$ & $-2,558$ \\
\hline $\begin{array}{l}240 \% \text { Sn' De Non_dominant } \\
\text { Taraf PT Ekstansiyon }\end{array}$ & $105,95 \pm 23,21$ & $81,02 \pm 9,14$ & $0,035^{\circ}$ & $-2,111$ \\
\hline $\begin{array}{l}60 \% \text { \$n' De Dominant Taraf } \\
\text { Fleksiyon/Ekstansiyon Oranı }\end{array}$ & $50,01 \pm 6,40$ & $48,77 \pm 5,54$ & 0,749 & $-0,320$ \\
\hline $\begin{array}{l}\text { 60\%'Sn' De Nop_Dominant Taraf } \\
\text { Fleksiyon/Ekstansiyon Oranı }\end{array}$ & $47,34 \pm 5,64$ & $54,17 \pm 11,11$ & 0,250 & $-1,151$ \\
\hline $\begin{array}{l}240^{\circ} / \text { Sn' De Dominant Taraf } \\
\text { Fleksiyon/Ekstansiyon Oranı }\end{array}$ & $63,57 \pm 8,14$ & $60,40 \pm 7,24$ & 0,406 & $-0,831$ \\
\hline $\begin{array}{l}240^{\circ} / \text { Sn' De Non_Dominant } \\
\text { Taraf Fleksiyon/Ekstansiyon } \\
\text { Oranı }\end{array}$ & $66,62 \pm 8,69$ & $59,75 \pm 9,39$ & 0,110 & $-1,597$ \\
\hline
\end{tabular}


Tablo 3. Sporcularının Diz Fleksiyon ve Ekstansiyon Kas Kuvveti Dominant-Nondominant Taraf Farkı Yüzdelerinin Karşılaştırılması

\begin{tabular}{|c|c|c|}
\hline & $\begin{array}{l}\text { Biathlon }(\mathrm{N}=7) \\
\mathrm{X} \pm \mathrm{SS}\end{array}$ & $\begin{array}{l}\text { Buz Hokeyi }(\mathrm{N}=7) \\
\mathrm{X} \pm \mathrm{SS}\end{array}$ \\
\hline $\begin{array}{l}\text { 60\% } / \text { Sn' De Fleksiyon Dominant-Non_Dominant } \\
\text { Taraf Farkı }\end{array}$ & $108,24 \pm 6,58$ & $94,14 \pm 7,43$ \\
\hline $\begin{array}{l}\text { 60\% } \\
\text { Taraf 'De Ekstansiyon Dominant-Nop_Dominant }\end{array}$ & $102,54 \pm 7,33$ & $104 \pm 13,25$ \\
\hline $\begin{array}{l}240^{\circ} / \mathrm{Sn}^{\prime} \text { 'De Fleksiyon Dominant-Non-Dominant } \\
\text { Taraf Farkı }\end{array}$ & $99,81 \pm 12,23$ & $106,58 \pm 12,12$ \\
\hline $\begin{array}{l}\text { 240\% Sn' De Ekstansiyon Dominant-Non- } \\
\text { Dominant Taraf Farkı }\end{array}$ & $104,28 \pm 12,50$ & $104,68 \pm 7,45$ \\
\hline
\end{tabular}

Available at: http://journalofsportsmedicine.org and http://dx.doi.org/10.5152/tjsm.2017.020 